\title{
Short-Chained Platinum Complex Catalyzed Hydrosilylation under Thermomorphic Conditions: Heterogeneous Phase Separation at Ice Temperature
}

\author{
Chiao-Fan Chiu ${ }^{1,2, \dagger}$, Jinn-Hsuan Ho ${ }^{3,+}{ }^{\text {, Eskedar Tessema }}{ }^{4}$, Yijing Lu ${ }^{4}$, Chia-Rui Shen ${ }^{5,6}$, Chang-Wei Lin ${ }^{7, *}$ \\ and Norman $\mathrm{Lu}^{4,8, *}$
}

check for

updates

Citation: Chiu, C.-F.; Ho, J.-H.; Tessema, E.; Lu, Y.; Shen, C.-R.; Lin, C.-W.; Lu, N. Short-Chained Platinum Complex Catalyzed Hydrosilylation under Thermomorphic Conditions: Heterogeneous Phase Separation at Ice Temperature. Molecules 2021, 26, 378. https://doi.org/10.3390/ molecules 26020378

Received: 19 December 2020 Accepted: 9 January 2021 Published: 13 January 2021

Publisher's Note: MDPI stays neutral with regard to jurisdictional clai$\mathrm{ms}$ in published maps and institutional affiliations.

Copyright: (C) 2021 by the authors. Licensee MDPI, Basel, Switzerland. This article is an open access article distributed under the terms and conditions of the Creative Commons Attribution (CC BY) license (https:// creativecommons.org/licenses/by/ $4.0 /)$.
1 Department of Pediatrics, Linkou Medical Center, Chang Gung Memorial Hospital, Taoyuan 333, Taiwan; chioufan2008@gmail.com

2 Graduate Institute of Clinical Medical Sciences, College of Medicine, Chang Gung University, Taoyuan 333, Taiwan

3 Department of Chemical Engineering, National Taiwan University of Technology, Taipei 106, Taiwan; jhho@mail.ntust.edu.tw

4 Institute of Organic and Polymeric Materials, National Taipei University of Technology, Taipei 106, Taiwan; eskedartessema18@gmail.com (E.T.); yijinglu@hotmail.com.tw (Y.L.)

5 Department of Medical Biotechnology and Laboratory Sciences, College of Medicine, Chang Gung University, Taoyuan 333, Taiwan; crshen@mail.cgu.edu.tw

6 Department of Ophthalmology, Linkou Medical Center, Chang Gung Memorial Hospital, Taoyuan 333, Taiwan

7 Department of Internal Medicine, Division of Pulmonary and Critical Care Medicine, Chang Gung Memorial Hospital \& Chang Gung University, Taoyuan 333, Taiwan

8 Development Center for Smart Textile, National Taipei University of Technology, Taipei 106, Taiwan

* Correspondence: naturewei@cgmh.org.tw (C.-W.L.); normanlu@mail.ntut.edu.tw (N.L.)

+ These authors contributed equally to this work.

Abstract: Homogeneous catalysts $\mathrm{PtCl}_{2}\left[5,5^{\prime}\right.$-bis- $\left(n-\mathrm{ClCF}_{2}\left(\mathrm{CF}_{2}\right)_{3} \mathrm{CH}_{2} \mathrm{OCH}_{2}\right)-2,2^{\prime}$-bpy] (2A) and $\mathrm{PtCl}_{2}\left[5,5^{\prime}-\right.$ bis- $\left(n-\mathrm{HCF}_{2}\left(\mathrm{CF}_{2}\right)_{3} \mathrm{CH}_{2} \mathrm{OCH}_{2}\right)-2,2^{\prime}$-bpy] (2B), which contained short fluorous chains, were synthesized and used in catalysis of hydrosilylation of alkynes. In these reactions the thermomorphic mode was effectively used to recover these catalysts from the reaction mixture up to eight cycles by taking advantage of heterogeneous phase separation at ice temperature. This kind of catalysis had previously been observed in fluorous catalysts of platinum containing about $50 \%$ F-content, but in this work the percentage of F-content is decreased to only about $30 \%$, by which we termed them as "very light fluorous". Our new type of catalyst with limited number of F-content is considered as the important discovery in the fluorous technology field as the reduced number of fluorine atoms will help to be able to comply the EPA 8-carbon rule. The metal leaching after the reaction has been examined by ICP-MS, and the testing results show the leaching of residual metal to be minimal. Additionally, comparing these results to our previous work, fluorous chain assisted selectivity has been observed when different fluorous chain lengths of the catalysts are used. It has been found that there exists fluorous chain assisted better selectivity towards $\beta-(E)$ form in the Pt-catalyzed hydrosilylation of non-symmetric terminal alkyne when the Pt catalyst contains short fluorous chain (i.e., 4 Cs). Phenyl acetylenes showed the opposite regioselectivity due to pi-pi interaction while using the same catalyst via Markovnikov's addition to form terminal vinyl silane, which is then a major product for Pt-catalyzed hydrosilylation of terminal aryl acetylene with triethylsilane. Finally, the kinetic studies indicate that the insertion of alkyne into the $\mathrm{Pt}-\mathrm{H}$ bond is the rate-determining step.

Keywords: heterogeneous separation; catalyst; fluorous; hydrosilylation; platinum; thermomorphic; recovery; selectivity 


\section{Introduction}

Developing recyclable catalysts, able to reduce the waste of expensive transition metals is one of the important issues in sustainable research. Generally, homogeneous catalysts have good catalytic activity but they have limitation on separation catalytic recovery [1], whereas heterogeneous catalysts are easily recyclable but with low catalytic activity [2-4] A valuable method, called thermomorphic system provides a good resolution which makes the catalyst dissolve in one condition but precipitate in another. Using the special solubility selectivity of fluorous chain-containing metal complex $[5,6]$ is very promising for the catalytic thermomorphic system in the development of fluorine chemistry [7].

Many polyfluorinated chain-containing metal complexes are used in the fluorous biphasic system (FBS) [8] which is an immiscible two-solvent system having one fluorous solvent and a common organic one. After reaction completion, the fluorous chaincontaining metal complexes can be easily extracted from the fluorous solvent while the other organic products stay in organic layer. To ensure the good solubility for fluorous chain-containing compounds soluble in fluorous solvents, "heavy fluorous content" [9] (more than 60\% fluorine content, F-content) is required. This may result in a big drawback [10]; that is the need for expensive fluorous starting material and the solvent. To reduce the F-content of compounds and fluorous solvent, an alternative way is to use the different solubility of "light fluorous compounds" (less than $60 \%$ of F-content) $[5,11]$ between high and low temperature in a common organic solvent. In this method, a fluorous chain-containing metal catalyst could be soluble at high temperature during the catalytic reactions, but insoluble at room temperature (or lower temperature) for the recovery of catalysts via a simple liquid-solid separation [12-17]. This is a typical application of "light fluorous" metal catalysts in the so-called "thermomorphic condition".

A variety of fluorous chain-containing metal complexes have been synthesized in our laboratory and studied for the possible applications [18,19]. In 2016, we have demonstrated the first example of using a fluorous chain-containing $\mathrm{Pt}$ complex with heavy fluorine content $\left\{\left[\mathrm{PtCl}_{2}\left[5,5^{\prime}\right.\right.\right.$-bis- $\left(n-\mathrm{C}_{11} \mathrm{~F}_{23} \mathrm{CH}_{2} \mathrm{OCH}_{2}\right)-2,2^{\prime}$-bpy] (3a), with $53 \%$ F-content for the Pt catalyst\} successfully catalyzed the hydrosilylation of alkynes in dibutyl ether (DBE) under thermomorphic condition [19]. The results of the catalytic hydrosilylation reaction showed high reaction yields, good turnover numbers and good recovery of the catalyst for up to 8 times of re-usage with very low leaching level of $\mathrm{Pt}$ (ca. $0.001 \%$ ).

The hydrosilylation of alkynes has been performed with a variety of metal catalysts, including $\mathrm{Pt}, \mathrm{Ir}, \mathrm{Ru}, \mathrm{Rh}$, and Co complexes, and usually produced three possible products, $\alpha, \beta-(E)$ and $\beta-(Z)$ isomers [20-29]. Generally, $\beta-(E)$ is the thermo-dynamically favored isomer and dominates in most researches using aliphatic and aryl alkynes, such as Lewis's work using Karstedt's Pt catalyst [30], Marko's work using N-heterocyclic carbene Pt(0) catalysts ( $>95 \%$ yield) [31], Ge's work using bisphosphine Co catalysts (60-90\% yield) [32], Jesus's work using water-soluble $N$-heterocyclic carbene $\mathrm{Pt}(0)$ Complexes as a recyclable catalyst (58-97\% yield) [33,34], and Mata's work using a recoverable Pt catalyst immobilized on the surface of graphene (80-99\% yield) [35]. Additionally, Chauhan and Sarkar's work using Pt-nanoparticle catalyst (95-98\% yield) [36] and Cai's work using a reusable $\mathrm{K}_{2} \mathrm{PtCl}_{4} / \mathrm{Xphos}-\mathrm{SO}_{3} \mathrm{Na} / \mathrm{PEG}-400 / \mathrm{H}_{2} \mathrm{O}$ system (72-93\% yield) [37] were reported to be efficient and recyclable to give $\beta-(E)$ vinylsilane. However, $\alpha$ isomer has also been achieved to be the major product in few studies, such as Corma's work, which only presented for aryl acetylenes, using ligand-free $\mathrm{Pt}_{3}$ cluster catalyst (65-93\% yield) [38], Trost's work using pentamethylcyclopentadiene Ru catalysts (61-92\% yield) [39], and Huang's work using iminopyridine-oxazoline Co catalyst (55-95\% yield) [40]. Additionally, Mori's work reported RhI-based catalyst which gave the $\beta-(Z)$ isomer as a dominant product for both aliphatic and aryl alkynes [41]. This study, which is focused on recoverable catalysis, successfully developed a new recyclable Pt catalyst $2 \mathrm{~A}$ under thermomorphic condition to afford only two isomeric products, $\alpha$ and $\beta-(E)$ isomers, with better yield $(>99 \%)$, where the major products usually being $\beta-(E)$ isomer for the aliphatic alkynes and $\alpha$-vinylsilanes 
for the aryl alkynes in the hydrosilylation of terminal alkynes. All the results with usual features are discussed below.

It is important [42] that we could further lower the F-content of catalyst, in a way that its F-content is even lower than that of so-called "light fluorous" catalyst; and is without compromising the separation effectiveness, so they become readily adapted to the conventional chemical and biochemical processes. In this work, the even shorter fluorous chain-containing platinum catalysts, $\left[\mathrm{PtCl}_{2}\left(5,5^{\prime}\right.\right.$-bis $\left(\mathrm{CH}_{2} \mathrm{OCH}_{2} \mathrm{C}_{4} \mathrm{~F}_{8} \mathrm{Cl}\right)-2,2^{\prime}$-bpy) $](2 \mathrm{~A})$ and $\left[\mathrm{PtCl}_{2}\left(5,5^{\prime}\right.\right.$-bis $\left(\mathrm{CH}_{2} \mathrm{OCH}_{2} \mathrm{C}_{4} \mathrm{~F}_{8} \mathrm{H}\right)-2,2^{\prime}$-bpy) $]$ (2B) with the even lower fluorine content (i.e., 31.0 and $33.4 \%$ F-content for $\mathbf{2 A}$ and $\mathbf{2 B}$, respectively.) have been synthesized and been applied to catalyze the hydrosilylation reactions of internal and terminal alkynes. To the best of our knowledge, this is the first example of the application of very short polyfluorinated Pt complexes as effective, recoverable hydrosilylation catalysts under thermomorphic condition showing heterogeneous phase separation at ice temperature. These "very light fluorous" Pt complexes 2A and 2B feature on homogeneously catalyzing reaction at high temperature in common organic solvent and turning to the heterogeneous precipitation at lower temperature under thermomorphic condition. Taking into consideration of their good catalytic capabilities and good thermal stability, these catalysts could be regarded as the very good alternatives to most of the homogeneous catalysts.

\section{Results and Discussion}

\subsection{Catalyst Synthesis}

The preparation of ligands bis-5,5'-(n-ClCF$\left.\left(\mathrm{CF}_{2}\right)_{3} \mathrm{CH}_{2} \mathrm{OCH}_{2}\right)-2,2^{\prime}-\mathrm{bpy}(\mathbf{1 A})$ and bis$5,5^{\prime}-\left(n-\mathrm{HCF}_{2}\left(\mathrm{CF}_{2}\right)_{3} \mathrm{CH}_{2} \mathrm{OCH}_{2}\right)-2,2^{\prime}$-bpy (1B) followed a literature procedure [43]. The ligand of $1 \mathrm{~A}$ or $1 \mathrm{~B}$ has the lower F-content (wt. \%), which is 42.6 and $47.2 \%$, respectively. The reaction of fluorinated bipyridine (bpy) ligands, $\mathbf{1 A}, \mathbf{1 B}$, with $\mathrm{K}_{2} \mathrm{PtCl}_{4}$ in $\mathrm{DMSO}$, as shown in Scheme 1 , resulted in the synthesis of Pt complexes $\mathrm{PtCl}_{2}\left[5,5^{\prime}\right.$-bis- $\left(n-\mathrm{ClC}_{4} \mathrm{~F}_{8} \mathrm{CH}_{2} \mathrm{OCH}_{2}\right)-2,2^{\prime}-$ bpy] (2A) and $\mathrm{PtCl}_{2}\left[5,5^{\prime}\right.$-bis- $\left(n-\mathrm{HC}_{4} \mathrm{~F}_{8} \mathrm{CH}_{2} \mathrm{OCH}_{2}\right)-2,2^{\prime}$-bpy] (2B) as red solids, respectively. Compounds of $\mathbf{2 A}$ and $2 \mathrm{~A}$ exhibit the F-content being 31.0 and $33.4 \%$, respectively; and are soluble in $\mathrm{Bu}_{2} \mathrm{O}$ at $120^{\circ} \mathrm{C}$ forming a red color solution. However, compounds $2 \mathrm{~A}$ and $2 \mathrm{~B}$ are insoluble in $\mathrm{Bu}_{2} \mathrm{O}$ at $25{ }^{\circ} \mathrm{C}$ (see Figures $\mathrm{S} 3$ and S4 \& Scheme S1). Complexes of $2 \mathrm{~A}$ and 2B are also abbreviated as $\mathbf{5 5 - 8} \mathbf{F C l}-\mathbf{P t C l}_{2}$ and $\mathbf{5 5 - 8} \mathbf{F H}-\mathbf{P t C l}_{2}$, respectively.

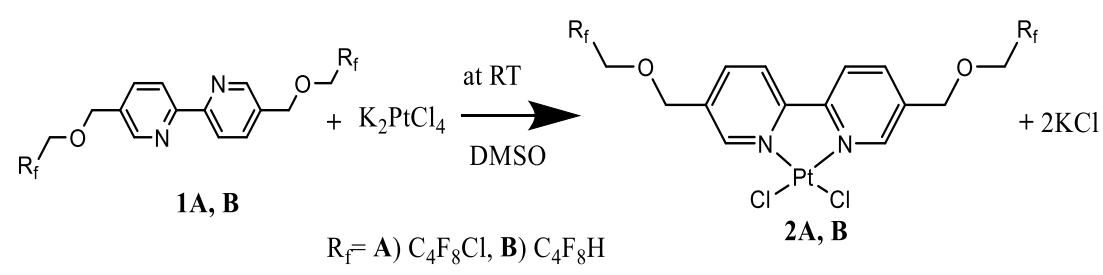

Scheme 1. Synthesis of the short fluorous chain Pt complexes.

\subsection{Recoverable Pt Complex-Catalyzed Hydrosilylation of Alkynes}

The fluorinated short-chained Pt complex $\mathbf{2 A}$ and $\mathbf{2 B}$ were then examined for the following experiments to catalyze the addition of $\mathrm{HSiEt}_{3}$ (3) to (a) symmetrical internal alkyne 5-decyne (4); (b) terminal alkynes 1-decyne (5), 1-hexyne (6) and functionalized terminal propargylic alkyne (7); and (c) aromatic terminal alkynes (8-10) in the following hydrosilylation reactions.

(a) Symmetrical internal alkyne

The Pt catalyst (2A or 2B)-catalyzed hydrosilylation of 5-decyne (4) with triethylsilane (3) under thermomorphic condition was successfully carried out to afford product $4 \mathbf{a}$ in quantitative conversions, as shown in Scheme 2, whereas no product 4a could be found in the reaction without using Pt catalyst for $24 \mathrm{~h}$. The best reaction condition for the catalyst $2 \mathrm{~A}$ was optimized at $120{ }^{\circ} \mathrm{C}$ for $2 \mathrm{~h}$ via the GC-MS examination of the reaction while the NMP was used as the internal standard. The quantitative conversion of the hydrosilylations were still observed even over the eight cycles of Pt catalyst recycling almost without decreasing 
the activity under the thermomorphic condition (Table 1). The similar catalytic effect on the converting yield is also shown by Pt catalyst 2B whose structure is to have $\mathrm{H}$ atom to replace $\mathrm{Cl}$ atom of $\mathbf{2 A}$ at the terminal of fluorous chains.
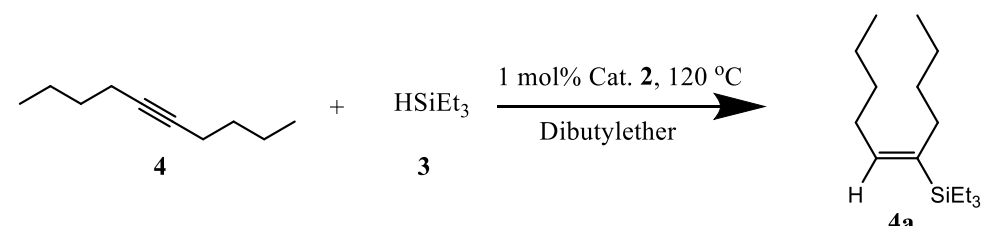

Scheme 2. The Pt catalyst (2A or 2B)-catalyzed hydrosilylation of 5-decyne (4) with triethylsilane (3) under thermomorphic condition.

Table 1. Hydrosilylation reactions of 5-decyne (4) and triethylsilane (3) in the presence of $2 \mathrm{~A}$ and 2B catalysts.

\begin{tabular}{|c|c|c|c|c|}
\hline \multirow[b]{2}{*}{ Run } & \multicolumn{2}{|c|}{$55-8 \mathrm{FCl}-\mathrm{PtCl}_{2}(2 \mathrm{~A})$} & \multicolumn{2}{|c|}{ 55-8FH-PtCl 2 (2B) } \\
\hline & Time (h) & Yield $(\%)^{a}$ & Time (h) & Yield $(\%)^{a}$ \\
\hline 1 & 2 & 100 & 2 & 100 \\
\hline 2 & 2 & $99(89)$ & 2 & 100 \\
\hline 3 & 2 & $100(94)$ & 2 & 94 \\
\hline 4 & 2 & 100 & 2 & $100(91)$ \\
\hline 5 & 2 & 100 & 2 & $100(94)$ \\
\hline 6 & 2 & 100 & 2 & 90 \\
\hline 7 & 2 & 100 & 2 & 100 \\
\hline 8 & 2 & 100 & 2 & 96 \\
\hline
\end{tabular}

Reaction conditions: Temp $=120^{\circ} \mathrm{C}$; cat $2 \mathrm{~A}$ or $\mathbf{2 B} 1 \mathrm{~mol} \%, 4(276 \mathrm{mg}, 2 \mathrm{mmol}), 3(232 \mathrm{mg}, 2 \mathrm{mmol})$, solvent: $2 \mathrm{~mL}$. a: Based on GC yield; isolated yields are given in parentheses.

Generally, catalysts with high F-content have good performance under thermomorphic condition, e.g., $\mathrm{PtCl}_{2}\left[5,5^{\prime}\right.$-bis- $\left(n-\mathrm{C}_{11} \mathrm{~F}_{23} \mathrm{CH}_{2} \mathrm{OCH}_{2}\right)-2,2^{\prime}$-bpy] (55-23F-PtCl 2 ) reported in our previous work (with $\mathrm{C}_{11} \mathrm{~F}_{23}$ moiety, $\% \mathrm{~F}=53$ ) [19], but the catalyst $2 \mathrm{~A}$ here only containing "very-light fluorous" chain (e.g., $\mathrm{C}_{4} \mathrm{~F}_{8}, \% \mathrm{~F}=31$ ) still showed the impressive catalytic activity and efficient recovery under thermomorphic condition (Figures S1 and S3) shown in Table 1.

Generally speaking, typical Pt-based catalysts for the hydrosilylation of alkynes can be used at significantly lower $\mathrm{Pt} /$ substrate ratios than $1 \mathrm{~mol} \%$ loading. We mainly use $1 \mathrm{~mol} \%$ of catalyst 2A loading because the scope of this study is on recycling and reuse of catalyst. The hydrosilylation of 5-decyne (4) with triethylsilane (3) was also reported by F. Alonso's group using $\mathrm{Pt} / \mathrm{TiO}_{2}$ as the catalyst by using more stringent catalytic loading of $0.25 \mathrm{~mol} \%$ [44]. They showed catalytic results under very short reaction time (less than $2 \mathrm{~h}$ ) at first two catalytic reaction cycles, but the catalyst's activity was significantly decreased to make the third-cycle reaction taking $3 \mathrm{~h}$ for the same conversion and the fifth-cycle reaction giving only $62 \%$ conversion after $24 \mathrm{~h}$. In contrast, the fifth-cycle hydrosilylation in our work still had very good performance of $99.5 \%$ conversion (entry 5 in Table 1), which indicates that $\mathrm{Pt}$ catalyst $\mathbf{2 A}$ is both very efficient and robust. The Pt catalyst $2 \mathrm{~A}$-catalyzed hydrosilylations of 5-decyne (4) with triethylsilane (3) in $\mathrm{Bu}_{2} \mathrm{O}$ have also been studied kinetically at 120 and $130{ }^{\circ} \mathrm{C}$. These two sets of data points are shown in Section S3 in Supplementary Materials. In both cases, the integrated rate law derived from the alkyne concentration vs time plots is $\ln \left[5-\right.$ decyne] $=\ln [5-\text { decyne }]_{0}-\mathrm{kt}$, with $\mathrm{k}=0.069\left(\mathrm{R}^{2}=0.95\right) \&$ $0.099\left(\mathrm{R}^{2}=0.99\right)$ at $120{ }^{\circ} \mathrm{C}$ and $130{ }^{\circ} \mathrm{C}$, respectively. [Note: $\ln [5-\text { decyne }]_{0}=0$ ]; at $130{ }^{\circ} \mathrm{C}$ the derived $\ln [5 \text {-decyne }]_{0}$ value is very close to 0$]$. The first reaction order with respect to the alkyne suggests that the insertion of the latter into the $\mathrm{Pt}-\mathrm{H}$ bond is the rate-determining step, in agreement with the recent results reported by Kuhn's group [45]. These two kinetically monitored reactions at $0.5 \mathrm{~h}$ show the respective turnover frequencies (TOF) are 174 and $198 \mathrm{~h}^{-1}$. These data show that $2 \mathrm{~A}$ is recoverable, robust and catalytically effective. 
The Pt catalyst 2A-catalyzed hydrosilylation of 5-decyne (4) and dimethylphenylsilane $\left(3^{\prime}\right)$ was also carried out in a shorter reaction time (ca. $40 \mathrm{~min}$ ) to afford only E-form product of $4 \mathrm{c}$ based on the GC-MS analysis, as shown in Scheme 3. The good recycling results under the thermomorphic condition were also confirmed by the nearly quantitative conversion of the hydrosilylation catalyzed by the reused Pt catalyst for up to eight cycles (Table 2) with very good turnover number $(\mathrm{TON}=\sim 100)$.

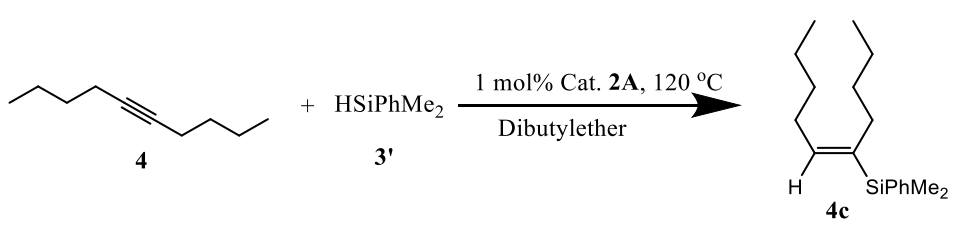

Scheme 3. The Pt catalyst 2A-catalyzed hydrosilylation of 5-decyne (4) with dimethylphenyl-silane $\left(3^{\prime}\right)$ under thermomorphic condition.

Table 2. Hydrosilylation reactions of 5-decyne (4) and dimethyl-phenylsilane ( $\left.3^{\prime}\right)$ under thermomorphic condition.

\begin{tabular}{ccc}
\hline Cycle & Time (h) & Yield (\%) $^{\mathbf{a}}$ \\
\hline 1 & 1 & 100 \\
2 & 1 & 98 \\
3 & 1 & $100(97)$ \\
4 & 1 & 100 \\
5 & 1 & 100 \\
6 & 1 & 100 \\
7 & 1 & $100(97)$ \\
8 & 1 & 100 \\
\hline
\end{tabular}

Reaction conditions: $\mathrm{T}=120^{\circ} \mathrm{C}$, cat. $2 \mathrm{~A}: 1 \mathrm{~mol} \%, 4(276 \mathrm{mg}, 2 \mathrm{mmol}), 3^{\prime}(272 \mathrm{mg}, 2 \mathrm{mmol})$, solvent: $2 \mathrm{~mL}$ a: Based on GC yield; isolated yields are given in parentheses.

(b) Terminal alkynes

b.1. Two terminal alkyl acetylenes

The Pt complex 2A-catalyzed hydrosilylation of triethylsilane (3) with terminal alkyne [i.e., 1-decyne (5) or 1-hexyne (6)] under thermomorphic mode is shown in Scheme 4 . The hydrosilylation of 1-decyne (5) with triethylsilane (3) afforded two products, triethyl(dec-1en-2-yl)silane (5a) and (E)-triethyl(dec-1-en-1-yl)silane (5b) with a GC-MS or NMR method to monitor the reaction and to determine the products under thermomorphic condition. This hydrosilylation also showed very good recycling results under thermomorphic condition. The structure of $\mathbf{5} \mathbf{a}$ and $\mathbf{5 b}$ were identified by the ${ }^{1} \mathrm{H}-\mathrm{NMR}$ spectrum of their mixture (see Figure S7). The signals of $\mathrm{H}_{\mathrm{a}}$ and $\mathrm{H}_{\mathrm{a}^{\prime}}$ of $5 \mathrm{a}$ are shown as two doublet peaks at 5.2 and $5.6 \mathrm{ppm}$ with a coupling constant of $2.7 \mathrm{~Hz}$, which is consistent to that of geminal alkenyl protons. For $5 \mathbf{b}$, the $\mathrm{H}_{\mathrm{b}^{\prime}}$ shows a doublet-triplet splitting peak and the $\mathrm{H}_{\mathrm{b}}$ shows a doublet peak with a coupling constant of $18.9 \mathrm{~Hz}$, which represents for the alkenyl protons at the trans position. The ratio of $\mathbf{5 a}$ and $\mathbf{5 b}$ determined from the integration of ${ }^{1} \mathrm{H}-\mathrm{NMR}$ spectrum equals to $1: 2$, which is almost similar to the ratio from GC-MS method (1:1.82) (see entry 5 in Table 3).

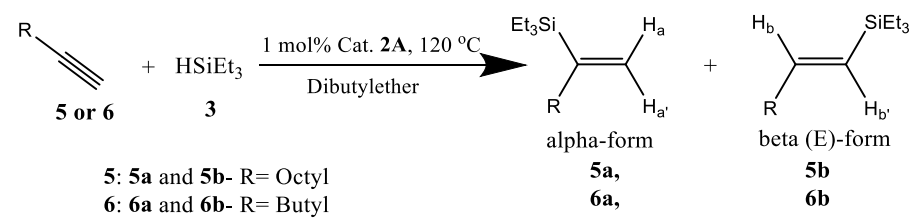

Scheme 4. The Pt complex 2A-catalyzed hydrosilylation of 1-decyne (5) or 1-hexyne (6) with triethylsilane (3) under thermomorphic condition. 
Table 3. Hydrosilylation reaction of 1-decyne (5) and triethylsilane (3) under thermomorphic condition.

\begin{tabular}{cccc}
\hline Cycle & Time (h) & $\mathbf{5 a : 5 b}$ & Yield (\%) $^{\mathbf{a}}$ \\
\hline 1 & 1 & $1: 1.58$ & 100 \\
2 & 1 & $1: 1.67$ & $100(96)$ \\
3 & 1 & $1: 1.48$ & $100(92)$ \\
4 & 1 & $1: 1.77$ & 100 \\
5 & 1 & $1: 1.82$ & $100(92)$ \\
6 & 1 & $1: 1.74$ & 100 \\
7 & 1 & $1: 1.40$ & $100(99)$ \\
8 & 1 & $1: 1.58$ & $100(91)$ \\
\hline
\end{tabular}

Reaction conditions: $\mathrm{T}=120^{\circ} \mathrm{C}$, cat. $2 \mathrm{~A} 1 \mathrm{~mol} \%, 5(276 \mathrm{mg}, 2 \mathrm{mmol}), 3(232 \mathrm{mg}, 2 \mathrm{mmol})$, solvent: $2 \mathrm{~mL}$. a: Based on GC yield; isolated yields are given in parentheses. The other terminal alkyne (1-hexyne (6)) recycling data are shown in Table S1 in Supplementary Materials.

The other terminal alkyne, 1-hexyne (6) also underwent the hydrosilylation reaction with triethylsilane (3) in the presence of Pt catalyst 2A successfully (Scheme 4). The reaction was completed within 30 min to produce two isomers $\alpha$-form $\mathbf{6 a}$ and $\beta$ - $(E)$-form $\mathbf{6 b}$ whose ${ }^{1} \mathrm{H}-\mathrm{NMR}$ spectrum shows similar characteristic peaks (see Figure S8) to that of $\alpha$-form 5 a and $\beta-(E)$-form $5 \mathbf{b}$. The signals for $\mathrm{H}_{\mathrm{a}}$ and $\mathrm{H}_{\mathrm{a}^{\prime}}$ of $\mathbf{6 a}$ are $5.3 \mathrm{ppm}(\mathrm{dt}, J=3.3,1.2 \mathrm{~Hz})$ and 5.6 ppm $(\mathrm{dt}, J=3.3,1.5 \mathrm{~Hz})$; and the signals for $\mathrm{H}_{\mathrm{b}}$ and $\mathrm{H}_{\mathrm{b}^{\prime}}$ of $6 \mathbf{b}$ are $5.5 \mathrm{ppm}(\mathrm{dt}, J=18.6$, $1.5 \mathrm{~Hz})$ and $6.0 \mathrm{ppm}(\mathrm{dt}, J=18.6,6.3 \mathrm{~Hz})$, respectively. As shown in entry $1 \mathrm{of}$ Table S1, the ratio of $\mathbf{6} \mathbf{a}$ and $\mathbf{6} \mathbf{b}$ is approximately 1:4.7 estimated by a GC-MS method.

b.2. One functionalized terminal alkyl acetylene (propargyl alcohol)

In Scheme 5, the hydrosilylation of 2-methylbut-3-yn-2-ol (7), a terminal alkyne with a bulky substituent (hydroxyisopropyl) with triethylsilane (3) for $1 \mathrm{~h}$ afforded two isomers, $\alpha$-form $7 \mathbf{a}$ and $\beta$ - $(E)$-form $7 \mathbf{b}$ in $99.4 \%$ yield with an estimated ratio of 1:2.1 from GC data, and/or 1:2.3 from ${ }^{1} \mathrm{H}-\mathrm{NMR}$ spectra. The good recycling results for this reaction were shown in Table 4 . When comparing with the previously reported long fluorous chained platinum complex $(\alpha: \beta=1: 2)$ [19], a slightly better selectivity was observed in this work by using $\mathrm{Pt}$ catalyst 2A (1:2.3). Although the heterogeneous catalyst $\mathrm{PtO} / \mathrm{PtO}_{2}-\mathrm{Fe}_{3} \mathrm{O}_{4}$ in literature [46] showed a better selectivity for $7 \mathbf{a}$ and $\mathbf{7 b}$ (1:3.5), it is worth mentioning that the Pt complex $2 \mathrm{~A}$ in this work still has good selectivity among a homogeneous type of catalysts.

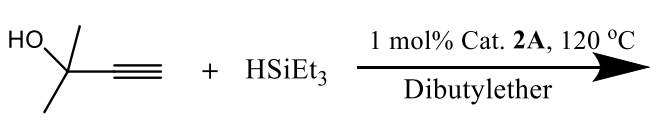

7

3

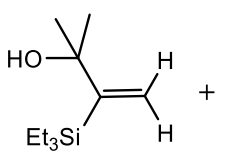

$7 \mathbf{a}$<smiles>CC/C=C\C(C)(C)O</smiles>

$7 \mathbf{b}$

Scheme 5. The Pt-catalyzed hydrosilylation reaction of 2-methylbut-3-yn-2-ol (7) and triethylsilane (3) under thermomorphic condition.

Table 4. Hydrosilylation reaction of 2-methylbut-3-yn-2-ol (7) and triethylsilane (3) under thermomorphic condition.

\begin{tabular}{cccc}
\hline Cycle & Time (h) & 7a:7b & Yield (\%) $\mathbf{a}$ \\
\hline 1 & 1 & $1: 2.1$ & $100(96)$ \\
2 & 1 & $1: 2.1$ & 99 \\
3 & 1 & $1: 2.0$ & $99(92)$ \\
4 & 1 & $1: 2.2$ & 99 \\
5 & 1 & $1: 2.1$ & 98 \\
6 & 1 & $1: 1.9$ & 100 \\
7 & 1 & $1: 2.0$ & 100 \\
8 & 1 & $1: 2.0$ & 99
\end{tabular}

Reaction conditions: $\mathrm{T}=120^{\circ} \mathrm{C}$, cat. $2 \mathrm{~A} 1 \mathrm{~mol} \%, 7(168 \mathrm{mg}, 2 \mathrm{mmol}), 3(232 \mathrm{mg}, 2 \mathrm{mmol})$, solvent: $2 \mathrm{~mL}$. a: Based on GC yield; isolated yields are given in parentheses. 
(c) Three terminal aryl acetylenes

In Scheme 6, the Pt catalyst 2A-catalyzed hydrosilylation of phenylacetylene (8) with triethylsilane (3) for 1 3 h under thermomorphic condition afforded two isomers, $\alpha$-form $8 \mathbf{a}$ and $\beta-(E)$-form $\mathbf{8 b}$ with an estimated ratio of $2: 1$ according to GC-MS analysis. The characteristic ${ }^{1} \mathrm{H}-\mathrm{NMR}$ signals (see Figure S9) for the geminal alkenyl protons of $\alpha$-form $8 \mathrm{a}$ appear at $5.6 \mathrm{ppm}(\mathrm{d}, J=3 \mathrm{~Hz})$ and $5.9 \mathrm{ppm}(\mathrm{d}, J=3 \mathrm{~Hz})$, and the signals for the trans position protons of $(E)$-form $8 \mathbf{b}$ show at $6.4 \mathrm{ppm}(J=18.9 \mathrm{~Hz})$ and $6.9 \mathrm{ppm}(J=19.5 \mathrm{~Hz})$. Most of the ratios of $\mathbf{8 a}$ and $\mathbf{8 b}$ determined by the integration of ${ }^{1} \mathrm{H}-\mathrm{NMR}$ spectrum are close to 2:1.

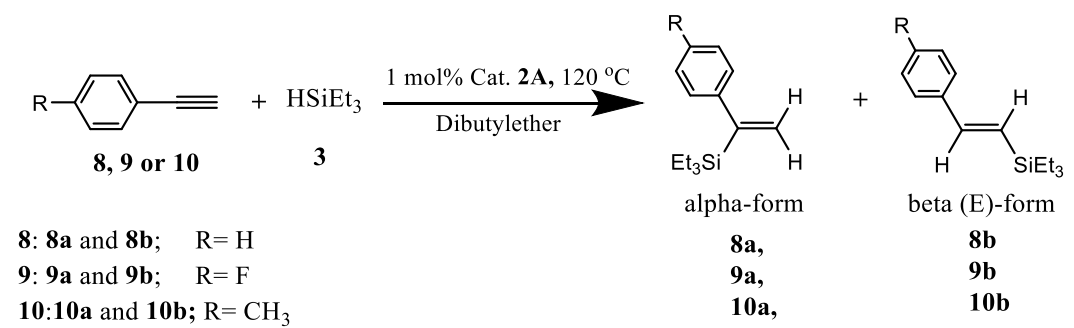

Scheme 6. The Pt complex 2A-catalyzed hydrosilylation of phenyl acetylenes (8 10) with triethylsilane (3).

Which is consistent to the ratio from GC-MS data in Table 5. Interestingly, the major product for the hydrosilylation of the terminal aryl acetylene (8) is thermodynamically unfavored $\alpha$-form $8 \mathbf{a}$, whereas the major products for the alkyl acetylenes $(5,6$ and 7$)$ are thermodynamically favored $\beta-(E)$-form $5 \mathbf{b}, \mathbf{6 b}$ and $7 \mathbf{b}$. The selectivity of ratio of $8 \mathbf{a}: \mathbf{8 b}$ decreased after 6 runs is because some of the catalysts start to degrade during the course of repeated reactions.

Table 5. Hydrosilylation reaction of phenylacetylene (8) and triethylsilane (3) under thermomorphic condition.

\begin{tabular}{cccc}
\hline Cycle & Time (h) & $\mathbf{8 a : 8 b}$ & Yield (\%) $^{\mathbf{a}}$ \\
\hline 1 & 2 & $2.02: 1$ & $99(92)$ \\
2 & 2 & $2.25: 1$ & $99(96)$ \\
3 & 2 & $2.26: 1$ & 99 \\
4 & 2 & $2.25: 1$ & $100(98)$ \\
5 & 2 & $2.21: 1$ & 100 \\
6 & 2 & $2.20: 1$ & 100 \\
7 & 2 & $1.86: 1$ & 100 \\
8 & 2 & $1.80: 1$ & 100 \\
\hline
\end{tabular}

Reaction conditions: $\mathrm{T}=120^{\circ} \mathrm{C}$, cat. $2 \mathrm{~A} 1 \mathrm{~mol} \%, 8(204 \mathrm{mg}, 2 \mathrm{mmol}), 3(232 \mathrm{mg}, 2 \mathrm{mmol})$, solvent: $2 \mathrm{~mL}$. a: Based on GC yield; isolated yields are given in parentheses.

When we compare the efficiency of our catalyst $2 \mathrm{~A}$ with a heterogeneous molecular complex immobilized on the surface of graphene, catalyst $2 \mathrm{~A}$ showed better catalytic efficiency at the elevated temperature. Mata [35] and his colleagues used $1 \mathrm{~mol} \%$ catalytic loading of their catalyst in the similar reactions to obtain $40 \%$ yield after $3 \mathrm{~h}$ where TON and TOF are 40 and 13, respectively. They have further optimized the reaction and used $0.5 \mathrm{~mol} \%$ loading to obtain $94 \%$ yield after $20 \mathrm{~h}$. Where TON and TOF are 188 and 9.4, respectively. However, we have obtained on average $100 \%$ yield in $2 \mathrm{~h}$ with TON and TOF values of 100 and 50, respectively.

According to the literatures, which isomer being the major product for the hydrosilylation of phenylacetylene depends on the different catalysts. The thermodynamically stable $\beta$-(E)-isomer was the major product when the hydrosilylation was catalyzed with a homogeneous Karstedt's catalyst at $60{ }^{\circ} \mathrm{C}$ for $1 \mathrm{~h}$, and the product ratio was $\beta-(E): \beta-(Z): \alpha$ isomers $=81: 1: 18$ [30]. However, the $\alpha$ isomer was the major product when it was catalyzed by a 
heterogeneous catalyst $\mathrm{Pt} / \mathrm{CeO}_{2}$ at $70{ }^{\circ} \mathrm{C}$ for $18 \mathrm{~h}$ [44] with the product ratio of $\beta-(E): \alpha=26: 74$ and the conversion $39 \%$ for THF and $50 \%$ for water as the solvents, respectively. Comparatively, using the Pt catalyst $2 \mathrm{~A}$ in this work which was homogeneous under thermomorphic mode, but provided thermodynamically unfavored $\alpha$-form as the major product with better conversions (mostly more than 99\%) and shorter reaction time (1 3 h).

Lastly, to further understand this unusual product selectivity, two more substituted phenyl acetylenes with electron-withdrawing fluoro group and electron-donating methyl group were brought to this $\mathbf{2 A}$ catalyzed hydrosilylation under thermomorphic mode. The hydrosilylation of 4-fluorophenylacetylene (9) at $120{ }^{\circ} \mathrm{C}$ for $4 \sim 5 \mathrm{~h}$ afforded $\alpha$-form isomer as the major product in $99 \%$ high yield with the product ratio of $9 a: 9 b=2.54: 1$ (estimated by GC) (Table S2). Similarly, the hydrosilylation of 4-methylphenylacetylene (10) at $120{ }^{\circ} \mathrm{C}$ for $2 \sim 5 \mathrm{~h}$ also produced $\alpha$-form isomer as the major product in $99 \%$ high yield with the product ratio of approximately $\mathbf{1 0 a}: \mathbf{1 0 b}=2.13: 1$ estimated by GC (entry 4, Table S3). The results of hydrosilylation reactions of either 4-fluorophenylacetylene (9) or 4-methylphenylacetylene (10) with triethylsilane (3) under thermomorphic conditions are shown Tables S2 and S3 in Supplementary Materials. No matter what kind of three substituents connected on the phenyl ring at para position, the thermodynamically less favored $\alpha$-form isomer would be the major product. Thus, Figure 1 and the related discussion below also explain the observed moderate regioselectivity of the 2A-catalyzed hydrosilylations of aryl and aliphatic acetylenes.

To understand the better product ratio from the Pt complex $2 \mathrm{~A}$-catalyzed hydrosilylation (short-fluorous-chains), a plausible mechanism containing the geometry of Pt complex was proposed. The optimized structure of $2 \mathrm{~A}$ in the gaseous phase has been obtained by DFT theoretical calculation, showing the two fluorous side-chains whose $-\mathrm{CH}_{2} \mathrm{OCH}_{2}-\mathrm{R}_{\mathrm{f}}$ moieties can form the two five-membered rings at the both sides of $5,5^{\prime}$-substituted bipyridine to extend the metal planarity (in Figure 1 and Figure S10 of Supplementary Materials). Similar type of extended the Pt metal planarity (with U-shaped like arrangement) has been found on the experimental data of 55-8FH-PtI2 (see Figure S11) in our previous research [47]. This optimized 2A arrangement also shows the intramolecular five-membered ring and other weak interactions (see Figure S10); and also be observed to be similar to that of the complexes 55-4FH-MX2, where $\mathrm{X}=\mathrm{Br}$ or I; $\mathrm{M}=\mathrm{Pt}$, with the loop structure reported by our group [48] (see Figure S12).

As shown is Figure 1 which is similar to Chalk-Harrod mechanism, the proposed mechanism for 2A-catalyzed hydrosilylation of terminal aliphatic alkyne with triethylsilane is described in a 3D-view instead of 2D-view of a well-known Chalk-Harrod mechanism. Firstly, in species I the $\mathbf{2 A}$ catalyst is believed to appear in the reduced form, $\mathrm{Pt}(0)$ [49] at the elevated temperature. Besides the planar $\mathrm{Pt}(\mathrm{bpy})$ core, the $\mathrm{Pt}$ complexes which contain two intramolecular five-membered ring in the species I, II, III and IV can extend its planarity with slight U-shaped structure. The $\mathrm{Et}_{3} \mathrm{SiH}$ is oxidatively added to [Pt], followed by coordination of the alkyne and insertion to $\mathrm{Pt}-\mathrm{H}$ bond. Thus, the electronic effect due to the polarization of an alkyne in hydrosilylation would direct the hydride addition to the more electropositive C-atom (in II). After the oxidative addition of silane, the alkyne is shown by approaching from the top of the $\mathrm{Pt}(\mathrm{bpy})$-based molecular plane. When the alkyne (the 2 nd reactant) has been attached to the Pt, this step of migration-insertion shows that the R group of the alkyne (III at bottom) has been forced to keep away from the silyl-group side of the metal complex (in IV) which then leads to generate $\beta-(E)$ form as the major product. This addition shows the anti-Markovnikov's selectivity. This proposed mechanism reasonably explains the better product ratio of $\beta-(E)$ to $\alpha$ in 1-decyne (5), 1-hexyne (6) and propargyl alcohol (7) in the hydrosilylations catalyzed by Pt catalyst 2A in this study. However, if the $\mathrm{R}$ group is the aromatic moiety, then the bond axis of the linear aryl acetylene molecule (H-C $\equiv \mathrm{C}-\mathrm{R}$ ) rotates more than $90^{\circ}$ with respect to $\mathrm{Pt}-\mathrm{b}$ axis (which is the molecular plane normal) (see Figure 1). For example, in an extreme case, if the tilting angle is equal to $180^{\circ}$, then it is like the linear molecule is exactly flipped over (R-C $\left.\equiv C-H\right)$. Such a phenomenon occurs possibly due to steric reason and other weak interactions (e.g., 
pi-pi interaction), when linear aromatic alkyne in species III is attached to the Pt center. Thus, 2A-catalyzed hydrosilylation of terminal aryl acetylenes with triethylsilane gives rise to the $\alpha$ isomer as the major product.

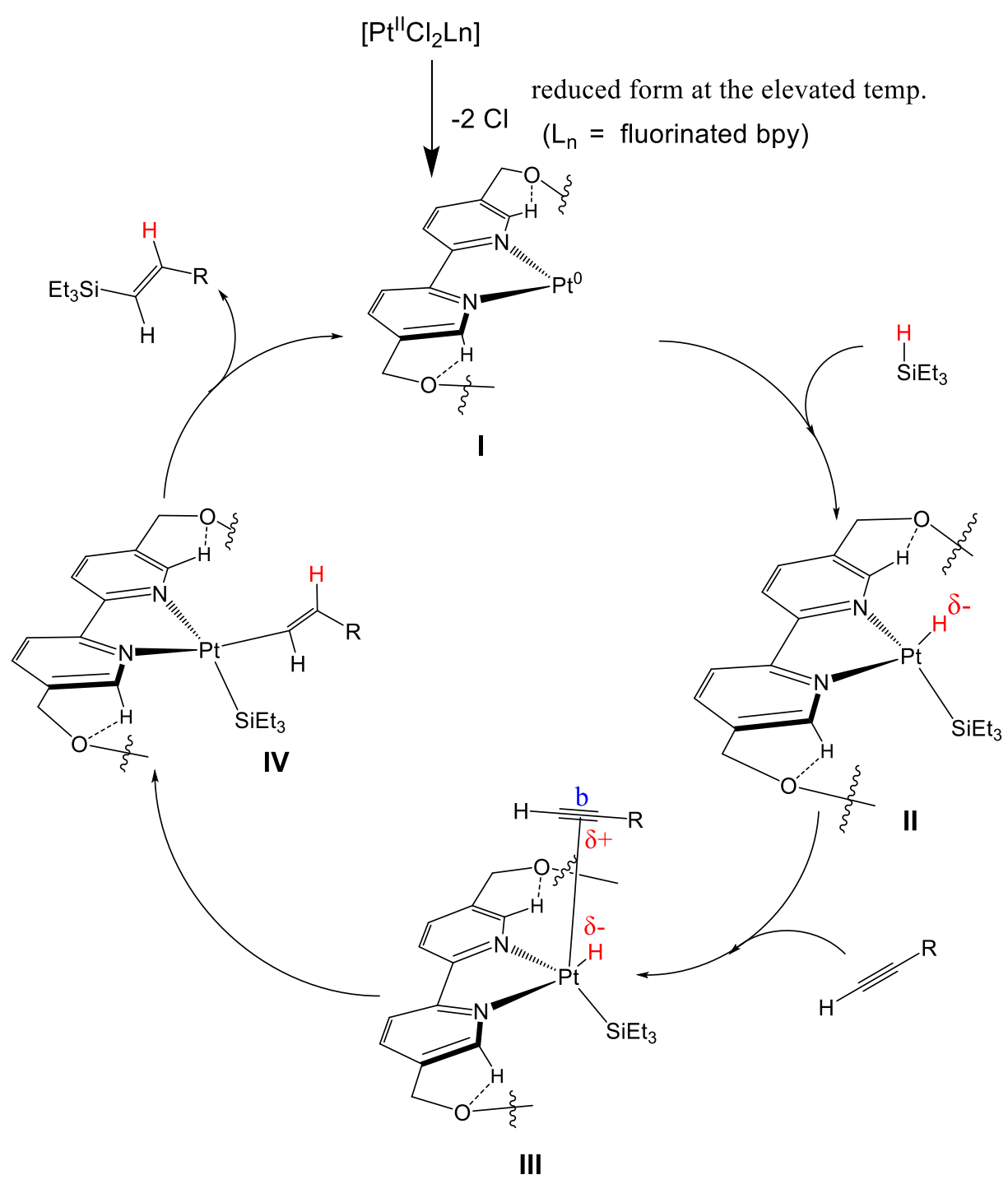

Figure 1. The proposed mechanism for 2A-catalyzed hydrosilylation of terminal (alkyl) alkyne with triethylsilane. (Note: $\mathrm{H}$ is labeled in red color).

\subsection{Detection of Metal Recovery by ICP-MS}

After discussing the hydrosilylation reaction of alkyne substrates, we randomly used ICP-MS to detect the leakage of metal catalysts, as shown in Table 6. The quantity of residual $\mathrm{Pt}$ metal present in the solution was analyzed, taking random samples among the product solutions resulting from the thermomorphic hydrosilylation. Only very low $\mathrm{Pt}$ leaching was observed in solution from the complex 2A- and 2B-catalyzed hydrosilylations under thermomorphic conditions. The residual platinum content in the product is only minimal since the recovery rate is greater than $99 \%$. Looking at the leaching test results, whether it is for $\mathbf{2 A}$ or $\mathbf{2 B}$, the measured platinum content is in the ppb level even after the 8 times of repeated recycling. It can be concluded that the metal catalyst used in this experiment not only effectively catalyzes hydrosilylation, but also easily achieved with almost no Pt leaching during the recycling processes. 
Table 6. Detection of platinum metal leakage by ICP-MS.

\begin{tabular}{ccccc}
\hline Table (\& Cycle) & Catalyst & Ppb $^{\mathbf{a}}$ & Leaching Level $\mathbf{( 1 0}^{-\mathbf{4}} \mathbf{~}^{\mathbf{b}}$ & Recovery (\%) \\
\hline $1-2$ & 2A & 517.5 & 6.63 & 99.93 \\
$1-3$ & 2A & 444.7 & 5.70 & 99.94 \\
$1-7$ & 2A & 137.1 & 1.76 & 99.98 \\
$1-8$ & 2A & 41.6 & 0.53 & 99.99 \\
$1-2$ & 2b & 21.7 & 0.28 & 99.99 \\
$1-3$ & 2B & 31.3 & 0.40 & 99.99 \\
$1-7$ & 2B & 56.6 & 0.72 & 99.99 \\
$1-8$ & 2B & 43.6 & 0.56 & 99.99 \\
$2-4$ & 2A & 29.9 & 0.38 & 99.99 \\
$3-2$ & 2A & 107.5 & 1.38 & 99.98 \\
$3-4$ & 2A & 79.4 & 1.02 & 99.98 \\
$3-6$ & 2A & 60.7 & 0.78 & 99.99 \\
S1-4 & 2A & 98.0 & 1.26 & 99.98 \\
S1-7 & 2A & 1753.0 & 22.50 & 99.77 \\
S1-8 & 2A & 2347.0 & 30.10 & 99.69 \\
$4-4$ & 2A & 276.5 & 3.54 & 99.96 \\
$5-4$ & 2A & 805.7 & 10.30 & 99.89 \\
\hline
\end{tabular}

a: (in ppb) detected from ICP-MS analysis for every $5 \mathrm{~mL}$ of sample solution which is diluted from $2 \mathrm{~mL}$ reaction mixture. $\mathrm{b}$ : The $\mathrm{Pt}$ leaching level is calculated as follows: taking entry 1-2 (Table 1-Cycle 2) for example: $(517.5 \mathrm{ppb} \times 5 \mathrm{~mL}) /(0.02 \mathrm{mmol} \mathrm{Pt})=517.5 \times(\mathrm{mg} \mathrm{Pt} / 103 \mathrm{~L}) \times 5 \times(10-3 \mathrm{~L}) /(2 \times 10-2 \times 195 \mathrm{mg} \mathrm{Pt})=6.63 \times 10^{-4}$. c: These three entries are shown in Table S1 in Supplementary Materials.

In order to evaluate the effect of a series of fluorous chain on the Pt catalyst recovery, the fluorinated moieties of $\mathrm{R}_{\mathrm{f}}=\mathrm{CF}_{3}, \mathrm{C}_{4} \mathrm{~F}_{8} \mathrm{Cl}\left(\mathrm{C}_{4} \mathrm{~F}_{8} \mathrm{H}\right), \mathrm{C}_{8} \mathrm{~F}_{16} \mathrm{H}$ and $\mathrm{C}_{11} \mathrm{~F}_{23}$ in the fluorous chain have been investigated for the systematic purpose. In other words, for the fluorous chains with $\mathrm{R}_{\mathrm{f}}=\mathrm{CF}_{3}$ and $\mathrm{C}_{8} \mathrm{~F}_{16} \mathrm{H}$ moieties which are from respective $\left[\mathrm{PtCl}_{2}\left(5,5^{\prime}\right.\right.$-bis $\left(\mathrm{CH}_{2} \mathrm{OCH}_{2} \mathrm{CF}_{3}\right)-2,2^{\prime}-$ bpy)] (2C) and [ $\mathrm{PtCl}_{2}\left(5,5^{\prime}\right.$-bis $\left(\mathrm{CH}_{2} \mathrm{OCH}_{2} \mathrm{C}_{8} \mathrm{~F}_{16} \mathrm{H}\right)-2,2^{\prime}$-bpy)] (2D) complexes have also studied to give a trend for the series (see Section $\mathrm{S} 7$ in Supplementary Materials). When $\mathrm{R}_{\mathrm{f}}=\mathrm{CF}_{3}$ group, it has been found that $55-3 \mathrm{~F}-\mathrm{PtCl}_{\mathbf{2}}(\mathbf{2 C})$ is totally soluble in DMF and moderately soluble in $\mathrm{Bu}_{2} \mathrm{O}$. The images of these solubility properties are shown in Section $\mathrm{S} 7$ of Supplementary Materials (see Figure S13a,b). Thus, complex 2C with one carbon fluoro-chain which is so short that it cannot give the useful heterogeneous phase separation property at room temperature for the recycling studies here. When $\mathrm{R}_{\mathrm{f}}=\mathrm{C}_{8} \mathrm{~F}_{16} \mathrm{H}$ group which is sparingly soluble in $\mathrm{Bu}_{2} \mathrm{O}$ ether (solubility image is shown in Figure S14 in Supplementary Materials).

Thus, 55-16 FH- $\mathrm{PtCl}_{2}$-catalyzed hydrosilylations of 5-decyne with $\mathrm{HSiEt}_{3}$ at $120{ }^{\circ} \mathrm{C}$ under thermomorphic mode have also been carried out. These results shown in Table S4

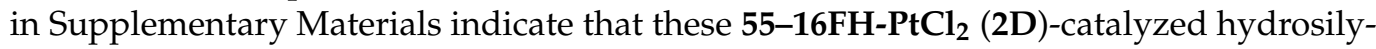
lations can take slightly longer than $3 \mathrm{~h}$ to complete. Thus, by comparing the reactivities from a series of Pt metal complexes which are 55-8FCl-PtCl 2 (2A), 55-16 FH- $\mathbf{P t C l}_{2}$ (see Section S7.2, Table S4 in Supplementary Materials) and 55-23F- $\mathbf{P t C l}_{2}$ [19], the rate due to the steric reasons follows the trend: the shorter the chain of fluorous catalyst, the faster the hydrosilylation.

\section{Experimental Section}

\subsection{General Procedures}

HP 6890 GC containing a $30 \mathrm{~m} 0.250 \mathrm{~mm}$ HP-1 capillary column with a $0.25 \mathrm{~mm}$ stationary phase film thickness was used to censor the reaction. The same GC instrument with a 5973 series mass selective detector was used to Acquire GC/MS data. The flow rate was $1 \mathrm{~mL} / \mathrm{min}$ and splitless. Samples analyzed by fast atom bombardment (FAB) mass spectroscopy were done by the staff of the National Central University (Taoyuan, Taiwan) mass spectrometry laboratory. The amounts of residual Pt samples were analyzed by ICP-MS. Infra-red spectra were obtained on a Perkin Elmer RX I FT-IR Spectrometer. NMR spectra were recorded on Bruker AM 500 and Joel AM 200 using $5 \mathrm{~mm}$ sample tubes. $\mathrm{CD}_{3} \mathrm{OD}, \mathrm{CD}_{2} \mathrm{Cl}_{2}, \mathrm{CDCl}_{3}$, deuterated DMF and deuterated DMSO were the references 
for both ${ }^{1} \mathrm{H}$ - and ${ }^{13} \mathrm{C}-\mathrm{NMR}$ spectra; and Freon ${ }^{\circledR} 11\left(\mathrm{CFCl}_{3}\right)$ was the reference for ${ }^{19} \mathrm{~F}$ NMR spectra.

\subsection{General Procedures in Catalytic Hydrosilylation Reaction and Recovery}

In a typical run, an alkyne $(2 \mathrm{mmol})$ and silane $(2 \mathrm{mmol})$ were charged into $10 \mathrm{~mL}$ reaction tube containing a magnetic stirrer bar, then the Pt catalyst $(1 \mathrm{~mol} \%)$ and followed by dibutyl ether, $\mathrm{DBE}$, solvent $(2 \mathrm{~mL})$. Then the reaction mixture was set to react at $120^{\circ} \mathrm{C}$ for the given period of time before GC/MS analysis was done to confirm the completion of the reaction. Once the catalytic recovery was done, the pure product was isolated by using $\mathrm{CH}_{2} \mathrm{Cl}_{2}$ /water extraction and the $\mathrm{CH}_{2} \mathrm{Cl}_{2}$ layer was pumped under reduced pressure to obtain the pure product. The product was finally analyzed by using ${ }^{1} \mathrm{H}-\mathrm{NMR}$ spectroscopy.

The Pt-catalyzed hydrosilylation reactions of all the alkyne substrates with 3 were carried out under the thermomorphic condition that effectively confirmed the practicability of reutilizing the catalyst in $\mathrm{Bu}_{2} \mathrm{O}$ solvent. Every round the catalytic reaction was performed at $120^{\circ} \mathrm{C}$ under $\mathrm{N}_{2}$ gas. At the end of each run, the product mixtures were put into freezer $\left(0{ }^{\circ} \mathrm{C}\right)$ for about $5 \mathrm{~min}$, and then centrifuged to separate the catalyst and reaction mixture (see Scheme S1 in Supplementary Materials). After catalyst was recovered by decantation and washed three times by the same solvent, it was again supplied with the same amounts of $\mathrm{Bu}_{2} \mathrm{O}$ solvent, the alkyne substrate, and $\mathrm{HSiEt}_{3}$ to continue to the next round. The products were tracked with GC-MS and ${ }^{1} \mathrm{H}-\mathrm{NMR}$, using NMP as internal standard until the end of the reaction was confirmed.

\subsection{Starting Materials}

Chemicals, reagents, and solvents employed were commercially available and used as received. $\mathrm{H}\left(\mathrm{CF}_{2}\right)_{4} \mathrm{CH}_{2} \mathrm{OH}$ and $\mathrm{Cl}\left(\mathrm{CF}_{2}\right)_{4} \mathrm{CH}_{2} \mathrm{OH}$ were purchased from either Aldrich or SynQuest.

\subsection{Preparation of Platinum Complexes}

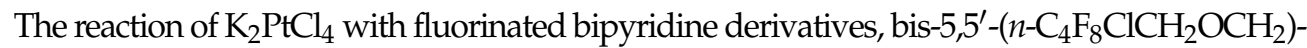
2,2'-bpy (1A) and bis-5, $5^{\prime}-\left(n-\mathrm{C}_{4} \mathrm{~F}_{8} \mathrm{HCH}_{2} \mathrm{OCH}_{2}\right)-2,2^{\prime}$-bpy (1B), resulted in the synthesis of $\mathrm{PtCl}_{2}\left[5,5^{\prime}\right.$-bis- $\left(n-\mathrm{C}_{4} \mathrm{~F}_{8} \mathrm{ClCH}_{2} \mathrm{OCH}_{2}\right)-2,2^{\prime}$-bpy] (2A) and $\mathrm{PtCl}_{2}$ [5, 5'-bis- $\left(n-\mathrm{C}_{4} \mathrm{~F}_{8} \mathrm{HCH}_{2} \mathrm{OCH}_{2}\right)$ 2,2'-bpy] (2B), as red solids. 1A or $\mathbf{1 B}(10.0 \mathrm{mmol}$; its synthesis see Supplementary Materials), $\mathrm{K}_{2} \mathrm{PtCl}_{4}(11.0 \mathrm{mmol})$ and DMSO $(2 \mathrm{~mL})$ were charged into $50 \mathrm{~mL}$ round-bottomed flask. The reaction was stirred under nitrogen at room temperature for $4 \mathrm{~h}$, and the complexes 2A and 2B would then precipitate from the reaction mixture [50-53]. After collection of the precipitates, water and $\mathrm{Et}_{2} \mathrm{O}$ were used to wash the red solids for several times, and the yields were $87 \%$ and $85 \%$, for $2 \mathbf{A}$ and $\mathbf{2 B}$, respectively.

\subsection{Analytical Data for Two Ligands and Their Platinum Metal Complexes (1A, 1B, 2A, 2B)}

55-8FCl-bpy (1A). Yield: 90\%. m.p.: $75^{\circ} \mathrm{C}$. FT-IR $\left(\mathrm{cm}^{-1}\right)$ : $v$ (bpy, m) 1600, 1557, 1466; $v$ $\left(\mathrm{CF}_{2}\right.$ stretch, s) 1182, 1112. ${ }^{1} \mathrm{H}-\mathrm{NMR}\left(300 \mathrm{MHz}, \mathrm{DMSO}_{\mathrm{d}}, \mathrm{rt}\right): \delta(\mathrm{ppm}) 8.65(\mathrm{~d}, J=1.5 \mathrm{~Hz}$, $2 \mathrm{H}, \mathrm{H} 6), 8.39(\mathrm{~d}, J=8.4 \mathrm{~Hz}, 2 \mathrm{H}, \mathrm{H} 3), 7.90(\mathrm{dd}, J=8.1 \mathrm{~Hz}, J=2.1 \mathrm{~Hz}, 2 \mathrm{H}, \mathrm{H} 4), 4.78(\mathrm{~s}, 4 \mathrm{H}$, bpy- $\left.\mathrm{CH}_{2}\right), 4.28\left(\mathrm{t}, J=7.35 \mathrm{~Hz}, 4 \mathrm{H},-\mathrm{CH}_{2} \mathrm{CF}_{2}-\right) ;{ }^{13} \mathrm{C}-\mathrm{NMR}\left(125 \mathrm{MHz}, \mathrm{DMSO}-\mathrm{d}_{6}, 350 \mathrm{~K}\right)$ : $\delta$ (ppm) 192.3, 186.2, 174.3, 170.5, 157.8 (10C, bpy), 161.6-144.2 $\left(-\mathrm{C}_{4} \mathrm{~F}_{8} \mathrm{Cl}\right), 108.4$ (bpy$\left.\mathrm{CH}_{2} \mathrm{O}-\right), 103.9\left(-\mathrm{CH}_{2} \mathrm{CF}_{2}-\right) ;{ }^{19} \mathrm{~F}-\mathrm{NMR}\left(470 \mathrm{MHz}, \mathrm{DMSO}-\mathrm{d}_{6}, 350 \mathrm{~K}\right): \delta(\mathrm{ppm})-68.4(\mathrm{t}$, $\left.J=14.1 \mathrm{~Hz}, 4 \mathrm{~F},-\mathrm{CF}_{2} \mathrm{Cl}\right),-118.8\left(\mathrm{t}, 4 \mathrm{~F},-\mathrm{CH}_{2} \mathrm{CF}_{2}\right),-120.2\left(\mathrm{~m}, 4 \mathrm{~F},-\mathrm{CF}_{2} \mathrm{CF}_{2} \mathrm{Cl}\right),-122.1$ $\left(\mathrm{s}, 4 \mathrm{~F},-\mathrm{CH}_{2} \mathrm{CF}_{2} \mathrm{CF}_{2}-\right) .713\left(\mathrm{M}^{+}\right), 463\left(\mathrm{M}^{+}-\mathrm{CH}_{2} \mathrm{C}_{4} \mathrm{~F}_{8} \mathrm{H}\right), 447\left(\mathrm{M}^{+}-\mathrm{OCH}_{2} \overline{\mathrm{C}}_{4} \mathrm{~F}_{8} \mathrm{H}\right), 182\left(\mathrm{M}^{+}-\right.$ $\left.\left(\mathrm{OCH}_{2} \mathrm{C}_{4} \mathrm{~F}_{8} \mathrm{H}\right)_{2}\right), \overline{91}\left(\mathrm{C}_{6} \mathrm{H}_{5} \mathrm{~N}\right)$.

55-8FH-bpy (1B). Yield: 80\%. m.p.: $68^{\circ} \mathrm{C}$. FT-IR $\left(\mathrm{cm}^{-1}\right)$ : $v$ (bpy, m) 1598, 1558, 1469; v $\left(\mathrm{CF}_{2}\right.$ stretch, s) 1159, 1126. ${ }^{1} \mathrm{H}-\mathrm{NMR}\left(300 \mathrm{MHz}, \mathrm{CDCl}_{3}, \mathrm{rt}\right): \delta(\mathrm{ppm}) 8.62(\mathrm{~s}, 2 \mathrm{H}, \mathrm{H6}), 8.41$ $(\mathrm{d}, J=8.2 \mathrm{~Hz}, 2 \mathrm{H}, \mathrm{H} 3), 7.80(\mathrm{~d}, J=8.2 \mathrm{~Hz}, 2 \mathrm{H}, \mathrm{H} 4), 6.04(\mathrm{tt}, J=51.9 \mathrm{~Hz}, J=5.5 \mathrm{~Hz}, 2 \mathrm{H}$, $\left.\mathrm{CF}_{2} \mathrm{H}\right), 4.70(\mathrm{~s}, 4 \mathrm{H}$, bpy-CH$), 3.99\left(\mathrm{t}, J=14.68 \mathrm{~Hz}, 4 \mathrm{H},-\mathrm{CH}_{2} \mathrm{CF}_{2}-\right) ;{ }^{13} \mathrm{C}-\mathrm{NMR}(125 \mathrm{MHz}$, $\left.\mathrm{CDCl}_{3}, 350 \mathrm{~K}\right): \delta$ (ppm) 121.0, 132.1, 136.5, 148.6, 155.9 (10C, bpy), 108.0-118.5 $\left(-\mathrm{C}_{4} \mathrm{~F}_{8} \mathrm{Cl}\right)$, 71.9 (bpy-CH $\left.\mathrm{CH}_{2} \mathrm{O}-\right), 67.0\left(-\mathrm{CH}_{2} \mathrm{CF}_{2}-\right) ;{ }^{19} \mathrm{~F}-\mathrm{NMR}\left(470 \mathrm{MHz}, \mathrm{CDCl}_{3}, 350 \mathrm{~K}\right): \delta$ (ppm) -137.2 
$\left(\mathrm{t}, J=13.7 \mathrm{~Hz}, 4 \mathrm{~F},-\mathrm{CF}_{2} \mathrm{H}\right),-119.5\left(\mathrm{t}, 4 \mathrm{~F},-\mathrm{CH}_{2} \mathrm{CF}_{2}\right),-125.4\left(\mathrm{~m}, 4 \mathrm{~F},-\mathrm{CF}_{2} \mathrm{CF}_{2} \mathrm{Cl}\right),-130.2(\mathrm{~s}$, $\left.4 \mathrm{~F},-\mathrm{CH}_{2} \mathrm{CF}_{2} \mathrm{CF}_{2}-\right)$. GC/MS: $644\left(\mathrm{M}^{+}\right), 429\left(\mathrm{M}^{+}-\mathrm{CH}_{2} \mathrm{C}_{4} \mathrm{~F}_{8} \mathrm{H}\right), 413\left(\mathrm{M}^{+}-\mathrm{OCH}_{2} \mathrm{C}_{4} \mathrm{~F}_{8} \mathrm{H}\right), 182$ $\left(\mathrm{M}^{+}-\left(\mathrm{OCH}_{2} \mathrm{C}_{4} \overline{\mathrm{F}_{8}} \mathrm{H}\right)_{2}\right), 91\left(\mathrm{C}_{6} \mathrm{H}_{5} \mathrm{~N}\right)$.

55-8FCl-PtCl 2 (2A). Yield: $87 \%$. Decomposed temperature $=315.5^{\circ} \mathrm{C}$. FT-IR $\left(\mathrm{cm}^{-1}\right): v$ (bpy, m) 1617, 1477; $v\left(\mathrm{CF}_{2}\right.$ stretch, s) $1180,1132,1103 .{ }^{1} \mathrm{H}-\mathrm{NMR}\left(500 \mathrm{MHz}, \mathrm{DMSO}-\mathrm{d}_{6}\right.$, rt): $\delta(\mathrm{ppm}) 9.47(\mathrm{~d}, J=1.8 \mathrm{~Hz}, 2 \mathrm{H}, \mathrm{H} 6), 8.56(\mathrm{~d}, J=8.1 \mathrm{~Hz}, 2 \mathrm{H}, \mathrm{H} 3), 8.32(\mathrm{dd}, J=8.7 \mathrm{~Hz}$, $J=1.8 \mathrm{~Hz}, 2 \mathrm{H}, \mathrm{H} 4), 4.92\left(\mathrm{~s}, 4 \mathrm{H}, \mathrm{bpy}-\mathrm{CH}_{2}\right), 4.36\left(\mathrm{t}, J=14.1 \mathrm{~Hz}, 4 \mathrm{H},-\mathrm{CH}_{2} \mathrm{CF}_{2}-\right) ;{ }^{13} \mathrm{C}-$ NMR (125 MHz, DMSO-d $\left.{ }_{6}, 350 \mathrm{~K}\right): \delta$ (ppm) 155.8, 146.9, 138.7, 137.2, 123.6 (10C, bpy), 148.3-120.1 (- $\left.\mathrm{C}_{4} \mathrm{~F}_{8} \mathrm{Cl}\right), 70.1$ (bpy-C $\left.\mathrm{CH}_{2} \mathrm{O}-\right)$, $66.8\left(-\mathrm{CH}_{2} \mathrm{CF}_{2}-\right)$; ${ }^{19} \mathrm{~F}-\mathrm{NMR}(470 \mathrm{MHz}$, DMSO$\left.\mathrm{d}_{6}, 350 \mathrm{~K}\right): \delta(\mathrm{ppm})-67.9\left(\mathrm{t}, J=14.1 \mathrm{~Hz}, 4 \mathrm{~F},-\mathrm{CF}_{2} \mathrm{Cl}\right),-118.5\left(\mathrm{t}, 4 \mathrm{~F},-\mathrm{CH}_{2} \mathrm{CF}_{2}\right),-119.7(\mathrm{~m}$, $4 \mathrm{~F},-\mathrm{CF}_{2} \mathrm{CF}_{2} \mathrm{Cl}$ ), - 121.6 (s, $4 \mathrm{~F},-\mathrm{CH}_{2} \mathrm{CF}_{2} \mathrm{CF}_{2}$-). HR-FAB: $\left(\mathrm{M}^{+}, m / z\right): \mathrm{C}_{22} \mathrm{H}_{14}{ }^{35} \mathrm{Cl}_{4} \mathrm{~F}_{16} \mathrm{~N}_{2} \mathrm{O}_{2} \mathrm{Pt}$ calculated: 976.9202 , found: $976.9207 ; \mathrm{C}_{22} \mathrm{H}_{14}{ }^{35} \mathrm{Cl}_{3}{ }^{37} \mathrm{ClF}_{16} \mathrm{~N}_{2} \mathrm{O}_{2} \mathrm{Pt}$ calculated: 978.9185 , found: $978.9183 ; \mathrm{C}_{22} \mathrm{H}_{14}{ }^{35} \mathrm{Cl}_{2}{ }^{37} \mathrm{Cl}_{2} \mathrm{~F}_{16} \mathrm{~N}_{2} \mathrm{O}_{2} \mathrm{Pt}$ calculated: 980.9185 , found: 980.9171 .

55-8FH-PtCl 2 (2B). Yield: $85 \%$. m.p.: $290^{\circ} \mathrm{C}$. FT-IR $\left(\mathrm{cm}^{-1}\right): v$ (bpy, m) 1672, 1477; $v\left(\mathrm{CF}_{2}\right.$ stretch, s) 1394, 1164, 1108. ${ }^{1} \mathrm{H}-\mathrm{NMR}(500 \mathrm{MHz}, \mathrm{DMSO}-\mathrm{d} 6, \mathrm{rt}): \delta$ (ppm) 9.49 (s, H6), 8.57 $(2 \mathrm{H}, \mathrm{d}, J=8.2 \mathrm{~Hz}, 2 \mathrm{H}, \mathrm{H} 3), 8.33(\mathrm{~d}, J=8.2 \mathrm{~Hz}, 2 \mathrm{H}, \mathrm{H} 4), 7.05(\mathrm{tt}, J=50.3 \mathrm{~Hz}, J=5.6 \mathrm{~Hz}$, $\left.2 \mathrm{H}, \mathrm{HCF}_{2}-\right), 4.94\left(4 \mathrm{H}, \mathrm{s}, \mathrm{bpy}-\mathrm{CH}_{2}\right), 4.33\left(4 \mathrm{H}, \mathrm{t}, J=14.8 \mathrm{~Hz},-\mathrm{CH}_{2} \mathrm{CF}_{2}-\right) ;{ }^{13} \mathrm{C}-\mathrm{NMR}(125 \mathrm{MHz}$, DMSO-d6, rt): $\delta$ (ppm) 156.0, 146.9, 139.0, 137.4, 123.9 (10C, s, bpy), 120.0-105.0 (8C, $\left.-\mathrm{C}_{4} \mathrm{~F}_{8} \mathrm{H}\right)$, $70.1(2 \mathrm{C}$, s, bpy-CH$), 66.6\left(2 \mathrm{C}, \mathrm{t}, J=24.5 \mathrm{~Hz},-\mathrm{CH}_{2} \mathrm{CF}_{2}-\right)$; 19F-NMR (470 MHz, DMSO-d6, rt): $\delta(\mathrm{ppm})-119.7\left(\mathrm{~m}, 4 \mathrm{~F},-\mathrm{CH}_{2} \mathrm{CF}_{2}-\right),-125.1\left(\mathrm{~s}, 4 \mathrm{~F},-\mathrm{CH}_{2} \mathrm{CF}_{2} \mathrm{CF}_{2}-\right),-130.1\left(\mathrm{~m}, 4 \mathrm{~F},-\mathrm{CF}_{2} \mathrm{CF}_{2} \mathrm{H}\right)$, $-138.8\left(\mathrm{~d}, 4 \mathrm{~F}, J=49.6 \mathrm{~Hz},-\mathrm{CF}_{2} \mathrm{H}\right)$. HR-FAB: $\left(\mathrm{M}^{+}, m / z\right) \mathrm{C}_{22} \mathrm{H}_{16}{ }^{35} \mathrm{Cl}_{2} \mathrm{~F}_{16} \mathrm{~N}_{2} \mathrm{O}_{2} \mathrm{Pt}$ calculated $m / z$ 908.9981, found 908.9985; $\mathrm{C}_{22} \mathrm{H}_{16}{ }^{35} \mathrm{Cl}^{37} \mathrm{ClF}_{16} \mathrm{~N}_{2} \mathrm{O}_{2} \mathrm{Pt}$ calculated $\mathrm{m} / \mathrm{z}$ 910.9952, found 910.9946; $\mathrm{C}_{22} \mathrm{H}_{16}{ }^{37} \mathrm{Cl}_{2} \mathrm{~F}_{16} \mathrm{~N}_{2} \mathrm{O}_{2} \mathrm{Pt}$ calculated $m / z$ 912.9922, found 912.9921 .

\section{Conclusions}

Concerns for the environment and scarcity of resources is becoming a challenge which motivates chemists to look for more economical and more ecofriendly process. Therefore, developing a recoverable catalyst with a better activity, better selectivity, and easier separation, with a better yield is everyone's goal. Reported here, this work showed effective catalysis by using shortest fluoro-chain complexes containing the (\%)F-content being less than $35 \mathrm{wt} . \%$. The catalyst was very effectively recycled up to eight times for all the experiments done, but almost without affecting its activity and selectivity. In these reactions the thermomorphic mode was effectively used to recover these short fluorous ponytailed catalysts from the reaction mixture up to eight cycles by using heterogeneous phase separation at $0{ }^{\circ} \mathrm{C}$. The product yield was also higher in every reaction run; sometimes it reached to even $100 \%$. The metal leaching studies via ICP-MS method showed that the metal in the complex is effectively recovered throughout the catalytic cycles with very little loss, which is almost negligible. Additionally, the kinetic studies have been carried out for 2A-catalyzed hydrosilylations of 5-decyne (4) with triethylsilane (3) in $\mathrm{Bu}_{2} \mathrm{O}$ at 120 and $130{ }^{\circ} \mathrm{C}$. The results showed that the 1 st order kinetics where the rate is directly proportional to the concentration of 5-decyne. Thus, we suggest that the insertion of alkyne into the $\mathrm{Pt}-\mathrm{H}$ bond is the rate-determining step which agrees well with recent results reported by Kuhn et al. [45]. Furthermore, the regioselectivity followed the Chalk-Harrod mechanism as it undergoes the syn kind of reaction to give $\alpha$ and $\beta-(E)$ products, of which the $\beta-(E)$ was the major form for most of the cases.

Supplementary Materials: The following are available online at, Figures S1-S4: thermomorphic property data, Figures S5 and S6: kinetic study, Figures S7-S9 ${ }^{1} \mathrm{H}-\mathrm{NMR}$ spectra of hydrosilylation products, Figures S10-S12: optimized structure from theoretical calculations, Tables S1-S4: recovery and recycling study. Scheme S1: The recycling procedure of the complex $2 \mathrm{~A}$ during the recoverable 2A-catalyzed hydrosilylation.

Author Contributions: N.L., J.-H.H., C.-R.S. performed the conceptualization and had the research idea; E.T. and Y.L. performed syntheses and characterization of the platinum complexes, and conducted the catalytic studies. E.T. and C.-F.C. studied the rate and mechanism of the catalytic reaction; 
N.L., C.-F.C. and C.-W.L. analyzed the obtained data and wrote the manuscript. All authors have read and agreed to the published version of the manuscript.

Funding: MOST 106-2113-M-027-001 and university joint grants: NTUT-CGMH-108-03 and NTUTCGMH-106-7 (or CORPG3G0071).

Data Availability Statement: The data presented in this study are available in the article and supplementary materials.

Acknowledgments: We gratefully acknowledge the Ministry of Science and Technology in Taiwan and university joint grants (NTUT-CGMH). Authors thank R. L. Sobocinski for proof-reading.

Conflicts of Interest: The authors declare no conflict of interest.

Sample Availability: Some of fluorous platinum metal complexes are available from the authors.

\section{References}

1. Dioumaev, V.K.; Bullock, R.M. A recyclable catalyst that precipitates at the end of the reaction. Nature 2003, 424, 530-532. [CrossRef] [PubMed]

2. Jankowska-Wajda, M.; Bartlewicz, O.; Walczak, A.; Stefankiewicz, A.R.; Maciejewski, H. Highly efficient hydrosilylation catalysts based on chloroplatinate "ionic liquids". J. Catal. 2019, 374, 266-275. [CrossRef]

3. Pospiech, P.; Chojnowski, J.; Mizerska, U.; Cempura, G. Platinum catalyst on polysiloxane microspheres with $N$-chelating groups. J. Mol. Catal. A Chem. 2016, 424, 402-411. [CrossRef]

4. Li, J.; Zhang, L.; Li, T.; Yang, C. Synthesis of a fumed silica-supported poly-3-(2-aminoethylamino) propylsiloxane platinum complex and its catalytic behavior in the hydrosilylation of olefins with triethoxysilane. Phosphorus Sulfur Silicon Relat. Elem. 2016, 191, 728-733. [CrossRef]

5. Curran, D.P.; Luo, Z. Fluorous synthesis with fewer fluorines (light fluorous synthesis): Separation of tagged from untagged products by solid-phase extraction with fluorous reverse-phase silica gel. J. Am. Chem. Soc. 1999, 121, 9069-9072. [CrossRef]

6. Dreimann, J.M.; Hoffmann, F.; Skiborowski, M.; Behr, A.; Vorholt, A.J. Merging thermomorphic solvent systems and organic solvent nanofiltration for hybrid catalyst recovery in a hydroformylation process. Ind. Eng. Chem. Res. 2017, 56, 1354-1359. [CrossRef]

7. Horváth, I.T. Fluorous Chemistry; Springer Science \& Business Media: Berlin/Heidelberg, Germany, 2011 ; Volume 308.

8. Horváth, I.T.; Rábai, J. Facile catalyst separation without water: Fluorous biphase hydroformylation of olefins. Science 1994, 266, 72-75. [CrossRef]

9. Zhang, W. Green chemistry aspects of fluorous techniques-Opportunities and challenges for small-scale organic synthesis. Green Chem. 2009, 11, 911-920. [CrossRef]

10. Vincent, J.-M.; Contel, M.; Pozzi, G.; Fish, R.H. How the Horváth paradigm, Fluorous Biphasic Catalysis, affected oxidation chemistry: Successes, challenges, and a sustainable future. Coord. Chem. Rev. 2019, 380, 584-599. [CrossRef]

11. Zhang, Q.; Luo, Z.; Curran, D.P. Separation of "light fluorous" reagents and catalysts by fluorous solid-phase extraction: Synthesis and study of a family of triarylphosphines bearing linear and branched fluorous tags. J. Org. Chem. 2000, 65, 8866-8873. [CrossRef]

12. Bergbreiter, D.E.; Osburn, P.L.; Wilson, A.; Sink, E.M. Palladium-catalyzed C-C coupling under thermomorphic conditions. J. Am. Chem. Soc. 2000, 122, 9058-9064. [CrossRef]

13. Zielinski, W.; Kukawka, R.; Maciejewski, H.; Smiglak, M. Ionic Liquids as Solvents for Rhodium and Platinum Catalysts Used in Hydrosilylation Reaction. Molecules 2016, 21, 1115. [CrossRef] [PubMed]

14. Dinh, L.V.; Gladysz, J. “Catalyst-on-a-Tape"-Teflon: A New Delivery and Recovery Method for Homogeneous Fluorous Catalysts. Angew. Chem. Int. Ed. 2005, 44, 4095-4097. [CrossRef]

15. Wende, M.; Gladysz, J. Fluorous catalysis under homogeneous conditions without fluorous solvents: A "greener" catalyst recycling protocol based upon temperature-dependent solubilities and liquid/solid phase separation. J. Am. Chem. Soc. 2003, 125, 5861-5872. [CrossRef]

16. Wende, M.; Meier, R.; Gladysz, J. Fluorous catalysis without fluorous solvents: A friendlier catalyst recovery/recycling protocol based upon thermomorphic properties and liquid/solid phase separation. J. Am. Chem. Soc. 2001, 123, 11490-11491. [CrossRef] [PubMed]

17. Qiao, Y.; Ma, W.; Theyssen, N.; Chen, C.; Hou, Z. Temperature-responsive ionic liquids: Fundamental behaviors and catalytic applications. Chem. Rev. 2017, 117, 6881-6928. [CrossRef]

18. Lu, N.; Chen, S.-C.; Chen, T.-C.; Liu, L.-K. Palladium-catalyzed Heck reaction under thermomorphic mode. Tetrahedron Lett. 2008, 49, 371-375. [CrossRef]

19. Lu, N.; Chung, W.-C.; Chiang, H.-F.; Fang, Y.-C.; Liu, L.-K. Recoverable platinum bis (fluoro-ponytailed) bipyridine complex as catalyst for hydrosilylation of alkynes under thermomorphic condition. Tetrahedron 2016, 72, 8508-8515. [CrossRef]

20. Diederich, F.; Stang, P.J. Metal-Catalyzed Cross-Coupling Reactions; John Wiley \& Sons: Hoboken, NJ, USA, 2008. 
21. Mori, A.; Takahisa, E.; Kajiro, H.; Hirabayashi, K.; Nishihara, Y.; Hiyama, T. $\mathrm{RhCl}\left(\mathrm{PPh}_{3}\right)_{3} / \mathrm{NaI}$ Catalyst System for Hydrosilylation of 1-Alkynes: Stereodivergent Syntheses of E-and Z-Alkenylsilanes with Heteroatom Substituents on Silicon. Chem. Lett. 1998, 27, 443-444. [CrossRef]

22. Mori, A.; Takahisa, E.; Kajiro, H.; Nishihara, Y.; Hiyama, T. Regio-and stereocontrolled hydrosilylation polyaddition catalyzed by $\mathrm{RhI}\left(\mathrm{PPh}_{3}\right)_{3}$. Syntheses of polymers containing (E)-or (Z)-alkenylsilane moieties. Macromolecules 2000, 33, 1115-1116. [CrossRef]

23. Sanada, T.; Kato, T.; Mitani, M.; Mori, A. Rhodium-Catalyzed Hydrosilylation of Internal Alkynes with Silane Reagents bearing Heteroatom Substituents. Studies on the Regio-/Stereochemistry and Transformation of the Produced Alkenylsilanes by Rhodium-Catalyzed Conjugate Addition. Adv. Synth. Catal. 2006, 348, 51-54. [CrossRef]

24. Mori, A.; Takahisa, E.; Nishihara, Y.; Hiyama, T. Isomerization of (Z)-alkenylsilanes to (E)-isomers with hydrosilane and RhI $\left(\mathrm{PPh}_{3}\right)_{3}$. Can. J. Chem. 2001, 79, 1522-1524. [CrossRef]

25. Mori, A.; Kato, T. unsaturated carbonyl compounds. Synlett 2002, 7, 1167-1169. [CrossRef]

26. Ojima, I.; Li, Z.; Zhu, J. The Chemistry of Organic Silicon Compounds; Patai, S., Rappoport, Z., Eds.; John Wiley and Son: New York, NY, USA, 1989; p. 1479.

27. Hiyama, T.T. Kusumoto in Comprehensive Organic Synthesis; Pergamon: Oxford, UK, 1991; Volume 8.

28. Trost, B.M.; Ball, Z.T.; Jöge, T. A chemoselective reduction of alkynes to (E)-alkenes. J. Am. Chem. Soc. 2002, 124, 7922-7923. [CrossRef]

29. Denmark, S.E.; Pan, W. Intramolecular anti-hydrosilylation and silicon-assisted cross-coupling: Highly regio-and stereoselective synthesis of trisubstituted homoallylic alcohols. Org. Lett. 2002, 4, 4163-4166. [CrossRef]

30. Lewis, L.N.; Sy, K.G.; Bryant, G.L., Jr.; Donahue, P.E. Platinum-catalyzed hydrosilylation of alkynes. Organometallics 1991, 10, 3750-3759. [CrossRef]

31. De Bo, G.; Berthon-Gelloz, G.; Tinant, B.; Markó, I.E. Hydrosilylation of alkynes mediated by N-heterocyclic carbene platinum (0) complexes. Organometallics 2006, 25, 1881-1890. [CrossRef]

32. Wu, C.; Teo, W.J.; Ge, S. Cobalt-catalyzed (e)-selective anti-Markovnikov hydrosilylation of terminal alkynes. ACS Catal. 2018, 8, 5896-5900. [CrossRef]

33. Silbestri, G.F.; Flores, J.C.; De Jesús, E. Water-soluble $N$-heterocyclic carbene platinum (0) complexes: Recyclable catalysts for the hydrosilylation of alkynes in water at room temperature. Organometallics 2012, 31, 3355-3360. [CrossRef]

34. Hitchcock, P.B.; Lappert, M.F.; Warhurst, N.J. Synthesis and Structure of a rac-Tris (divinyldisiloxane) diplatinum (0) Complex and its Reaction with Maleic Anhydride. Angew. Chem. Int. Ed. Engl. 1991, 30, 438-440. [CrossRef]

35. Mollar Cuni, A.; Borja, M.P.; Guisado-Barrios, G.; Mata Martínez, J.A. A Platinum molecular complex immobilised on the surface of graphene as active catalyst in alkyne hydrosilylation. EurJIC 2020, 45, 4254-4262.

36. Chauhan, B.P.; Sarkar, A. Functionalized vinylsilanes via highly efficient and recyclable Pt-nanoparticle catalysed hydrosilylation of alkynes. Dalton Trans. 2017, 46, 8709-8715. [CrossRef] [PubMed]

37. Xu, C.; Huang, B.; Yan, T.; Cai, M. A recyclable and reusable $\mathrm{K}_{2} \mathrm{PtCl}_{4}$ Xphos-SO ${ }_{3} \mathrm{Na} / \mathrm{PEG}-400 / \mathrm{H}_{2} \mathrm{O}$ system for highly regio-and stereoselective hydrosilylation of terminal alkynes. Green Chem. 2018, 20, 391-397. [CrossRef]

38. Rivero-Crespo, M.A.; Leyva-Pérez, A.; Corma, A. A Ligand-Free Pt3 Cluster Catalyzes the Markovnikov Hydrosilylation of Alkynes with up to 106 Turnover Frequencies. Chem. A Eur. J. 2017, 23, 1702-1708. [CrossRef] [PubMed]

39. Trost, B.M.; Ball, Z.T. Markovnikov alkyne hydrosilylation catalyzed by ruthenium complexes. J. Am. Chem. Soc. 2001, 123, 12726-12727. [CrossRef]

40. Zuo, Z.; Yang, J.; Huang, Z. Cobalt-catalyzed alkyne hydrosilylation and sequential vinylsilane hydroboration with markovnikov selectivity. Angew. Chem. Int. Ed. 2016, 55, 10839-10843. [CrossRef]

41. Mori, A.; Takahisa, E.; Yamamura, Y.; Kato, T.; Mudalige, A.P.; Kajiro, H.; Hirabayashi, K.; Nishihara, Y.; Hiyama, T. Stereodivergent syntheses of $(Z)$-and (E)-alkenylsilanes via hydrosilylation of terminal alkynes catalyzed by rhodium (I) iodide complexes and application to silicon-containing polymer syntheses. Organometallics 2004, 23, 1755-1765. [CrossRef]

42. Ubeda, M.A.; Dembinski, R. Fluorous compounds and their role in separation chemistry. J. Chem. Educ. 2006, 83, 84-92. [CrossRef]

43. Lu, N.; Ou, Y.-M.; Feng, T.-Y.; Cheng, W.-J.; Tu, W.-H.; Su, H.-C.; Wang, X.; Liu, L.; Hennek, M.D.; Sayler, T.S. Synthesis and characterization of polyfluorinated 2, 2'-bipyridines and their palladium and platinum complexes, $\left[\mathrm{MX}_{2}\left(\mathrm{bis}_{\mathrm{s}}\left(\mathrm{R}_{\mathrm{f}} \mathrm{CH}_{2} \mathrm{OCH}\right)^{2}-2\right.\right.$, $2^{\prime}$-bpy)](X = Cl, Br). J. Fluor. Chem. 2012, 137, 54-63. [CrossRef]

44. Alonso, F.; Buitrago, R.; Moglie, Y.; Ruiz-Martínez, J.; Sepúlveda-Escribano, A.; Yus, M. Hydrosilylation of alkynes catalysed by platinum on titania. J. Organomet. Chem. 2011, 696, 368-372. [CrossRef]

45. Meister, T.K.; Riener, K.; Gigler, P.; Stohrer, J.R.; Herrmann, W.A.; Kühn, F.E. Platinum Catalysis Revisited: Unraveling Principles of Catalytic Olefin Hydrosilylation. ACS Catal. 2016, 6, 1274-1284. [CrossRef]

46. Cano, R.; Yus, M.; Ramón, D.J. Impregnated platinum on magnetite as an efficient, fast, and recyclable catalyst for the hydrosilylation of alkynes. ACS Catal. 2012, 2, 1070-1078. [CrossRef]

47. Lu, N.; Zheng, J.H.; Lin, L.C.; Liu, L.K.; Chiang, H.F.; Li, T.Y.; Wen, Y.S.; Yang, C.K.; Chen, S.W.; Thrasher, J.S. Studies of two different types of intramolecular $\mathrm{C}-\mathrm{H} \cdots \mathrm{F}-\mathrm{C}$ interactions from polyfluorinated diiodometal (II) diimine complexes. J. Chin. Chem. Soc. 2019, 66, 31-40. [CrossRef]

48. Lu, N.; Lu, Y.J.; Huang, J.Y.; Chiang, H.F.; Kung, C.C.; Wen, Y.S.; Liu, L.K. The Evolution Aspect in the Crystallization Process of [5,5'-( $\left.\mathrm{HCF}_{2} \mathrm{CF}_{2} \mathrm{CH}_{2} \mathrm{OCH}_{2}\right)_{2}-2,2^{\prime}$-bpy] $\mathrm{MX}$ ( $(\mathrm{M}=\mathrm{Pt}, \mathrm{Pd} ; \mathrm{X}=\mathrm{I}, \mathrm{Br})$ : Role of the Intramolecular $\mathrm{CF}_{2}-\mathrm{HX}(-\mathrm{M})$ Hydrogen Bonds. J. Chin. Chem. Soc. 2018, 65, 613-627. [CrossRef] 
49. Islamova, R.M.; Dobrynin, M.V.; Ivanov, D.M.; Vlasov, A.V.; Kaganova, E.V.; Grigoryan, G.V.; Kukushkin, V.Y. bis-Nitrile and bis-dialkylcyanamide platinum (II) complexes as efficient catalysts for hydrosilylation cross-linking of siloxane polymers. Molecules 2016, 21, 311. [CrossRef] [PubMed]

50. Howell, J.L.; Lu, N.; Friesen, C.M. New derivatives of poly-hexafluoropropylene oxide from the corresponding alcohol. J. Fluor. Chem. 2005, 126, 281-288. [CrossRef]

51. Lu, N.; Tu, W.H.; Hou, H.C.; Lin, C.T.; Li, C.K.; Liu, L.K. Synthesis, structure and spectroelectrochemical property of $\left(2,2^{\prime}-\right.$ bipyridine)-metal ( $\mathrm{M}=\mathrm{Pt}, \mathrm{Pd}$ ) dichloride with 4,4'-bis (fluorous-ponytail) on bipyridine. Polyhedron 2010, 29, 1123-1129. [CrossRef]

52. Li, C.-K.; Ghalwadkar, A.; Lu, N. Recoverable cationic Pd-catalyzed Heck reaction under thermomorphic mode. J. Organomet. Chem. 2011, 696, 3637-3642. [CrossRef]

53. Periyanagounder, D.; Wei, T.C.; Li, T.Y.; Lin, C.H.; Gonçalves, T.P.; Fu, H.C.; Tsai, D.S.; Ke, J.J.; Kuo, H.W.; Huang, K.W.; et al. Fast-Response, Highly Air-Stable, and Water-Resistant Organic Photodetectors Based on a Single-Crystal Pt Complex. Adv. Mater. 2020, 32, 1904634. [CrossRef] 